\title{
Application of Scientific Adjustment of Taijiquan Exercise Load in Forest Park
}

\author{
Wang Youjun \\ Jiaozuo University Department of Taichi and Martial Arts, Jiaozuo,Henan, China
}

\begin{abstract}
:
This paper studies the energy consumption and its influencing factors of a set of simplified 24 Style Taijiquan with a time of five minutes. Therefore, this paper studies the scientific adjustment of Taijiquan exercise load in Forest Park, and points out the characteristics and differences of energy consumption among different groups of practitioners. At the same time, this paper studies the characteristics and differences of load intensity of Taijiquan practitioners in different groups and different postures, and establishes the regression equation of simplified 24 Style Taijiquan energy consumption. At the same time, this paper establishes a simplified mass fitness load standard of 24 Style Taijiquan, which provides more theoretical and data support for mass scientific, effective and safe fitness.
\end{abstract}

Keywords: Forest Park, Forest Environment, Taijiquan, Exercise Load.

\section{INTRODUCTION}

In China, Taijiquan absorbs Yin and Yang, Confucianism, health preservation and other Chinese traditional culture, which is rich in cultural connotation [1-2]. As an excellent cultural heritage of the Chinese nation, Taijiquan has a broad mass base. Because it has the characteristics of softness, slowness, rhythm and coordination, it can meet the requirements of public fitness, especially the middle-aged and elderly. Therefore, with the advent of China's aging, more and more people will choose this unique fitness method with Chinese characteristics. Widely promoting Taijiquan fitness will help to achieve the goal of national fitness with Chinese characteristics. However, in recent years, the problems of sports injury and sudden death in the field of fitness have also received universal attention [3]. The reason for these problems is that people blindly determine the amount of exercise according to their own feelings or exercise time in the process of exercise. There is no scientific guidance from professionals, and different exercise plans are not implemented according to the different needs, physique and stages of fitness workers [4-6]. Therefore, this paper hopes to study from the 
Article History: Received: 28 October 2021 Revised: 05 December 2021 Accepted: 10 January 2022 Publication: 28 February 2022

perspective of energy consumption, trying to put forward scientific and safe fitness standards and recommendations for public fitness in terms of energy consumption [7].

\section{RESEARCH OBJECT AND METHOD}

\section{Research object}

Measure the energy consumption of simplified 24 Style Taijiquan of Taijiquan practitioners in parks, communities and Beijing University of physical education. Through the analysis of the original data, this paper studies the characteristics of energy consumption of simplified 24 Style Taijiquan, different posture load intensity and scientific fitness load standard.

\section{Influencing Factors of Energy Consumption}

The influencing factors of energy consumption include many aspects, including basic metabolism, physical activity, mental and psychological factors [8]. Among them, basic metabolism is the minimum energy consumption of human life maintenance activities, that is, the energy consumption of human body in lying still, relaxing and awake state after fasting for 12 hours under quiet or constant temperature conditions. The influencing factors of basic metabolism mainly include age, height, weight and so on; The energy consumption of physical exercise is mainly affected by the load and load intensity. Generally speaking, the load and load intensity are directly proportional to the energy consumption; The influence of mental state and psychological state on energy consumption in physical activities can not be ignored, but this aspect is not easy to control, so this paper mainly considers the influence of height, weight, age, gender and training years on energy consumption. In terms of physiological indexes, the factors affecting energy consumption mainly include the functional status of cardiovascular system, respiratory system and central nervous system. Long-term Taijiquan exercise can also improve the function of the above-mentioned body system [9]. A large number of studies have proved that because the practice of Taijiquan requires the coordination of upper and lower limbs, the brain central nervous system is in a state of actively maintaining balance for a long time. Longterm Taijiquan exercise can improve the function of individual central nervous system and nervous system; Taijiquan exercise can improve the body's endurance, cholesterol, lipoprotein and reduce triglyceride. Adhering to Taijiquan exercise for a long time can improve cardiovascular function; Because Taijiquan is mainly abdominal breathing exercise based on diaphragm, long-term regular Taijiquan exercise can effectively improve lung ventilation and ventilation function and cardiopulmonary function [10].

The factors affecting energy consumption mainly include serum creatine kinase and blood urea nitrogen in blood. A large number of experimental studies show that serum creatine kinase and blood urea nitrogen can directly reflect the exercise intensity and objectively reflect the characteristics of energy consumption during exercise. In short, if serum creatine stimulation is found to be at a high level after exercise, it indicates that the load intensity is large and the 
Article History: Received: 28 October 2021 Revised: 05 December 2021 Accepted: 10 January 2022 Publication: 28 February 2022

energy consumption level is high. If the concentration of blood urea nitrogen is high, it indicates that the load density and load intensity are high.

Taijiquan is a middle and low intensity sport, which is very suitable for the fitness requirements of the middle-aged and elderly. On the contrary, there are few research results in the public fitness load standard. Therefore, it is very necessary to formulate a set of Taijiquan practice standard suitable for public fitness. Since the reform and opening up, people's material and cultural living standards have been continuously improved, and Chinese people pay more and more attention to health problems. However, people have been troubled by the standard of scientific physical activity load intensity and load intensity. On the other hand, because the load and load intensity are difficult to be controlled by data, more and more researchers begin to start from the perspective of energy consumption, Trying to provide scientific data and theoretical support for mass fitness. As early as the 1950s, foreign scholars began to study the energy consumption of sports activities, but in terms of sports, there was less research on the energy consumption of Taijiquan. The research on the energy consumption of Taijiquan in China was basically in its infancy. The energy consumption of Taijiquan is mainly studied by measuring physiological and biochemical indexes.

3. Expert interview method

According to the research needs, on the basis of consulting literature and books, the problems encountered in this process were outlined, and then the expert teachers of Beijing Sports University, Beijing University of science and technology, Henan University of technology and Anyang Normal University were interviewed. It also solicits relevant opinions and suggestions on the experimental design and data analysis of the paper, and further determines the value and feasibility of this paper in the research. The expert interviews are shown in Table 1.

TABLE I. THE EXPERT INTERVIEWS

\begin{tabular}{|l|l|l|l|}
\hline \multicolumn{1}{|c|}{$\begin{array}{c}\text { FULL } \\
\text { NAME }\end{array}$} & \multicolumn{1}{|c|}{ SCHOOL } & \multicolumn{1}{|c|}{ PROFESSIONAL } & \multicolumn{1}{c|}{ TITLE } \\
\hline Liu XX & $\begin{array}{l}\text { Beijing University of science and } \\
\text { technology }\end{array}$ & Physical education & $\begin{array}{l}\text { Associate } \\
\text { professor }\end{array}$ \\
\hline Liu XX & Henan University of Technology & Physical education & $\begin{array}{l}\text { Associate } \\
\text { professor }\end{array}$ \\
\hline Wang XX & Henan University of Technology & $\begin{array}{l}\text { National Traditional } \\
\text { Sports }\end{array}$ & $\begin{array}{l}\text { Associate } \\
\text { professor }\end{array}$ \\
\hline Guo XX & Anyang Normal University & Exercise rehabilitation & $\begin{array}{l}\text { Associate } \\
\text { professor }\end{array}$ \\
\hline
\end{tabular}

4. Test method 
Article History: Received: 28 October 2021 Revised: 05 December 2021 Accepted: 10 January 2022 Publication: 28 February 2022

The principle of measuring energy consumption by direct calorimetry and indirect calorimetry is derived from thermodynamics, while the principle of accelerometer is Newton's mechanical law. Because physical activities have dynamic properties, muscles maintain a certain tension in both dynamic and static properties, The acceleration sensor can evaluate the energy consumption of the body by measuring the integral of the absolute value of acceleration. The working principle of ideea is to sense the change of acceleration during walking through the acceleration sensor, measure its shape variable through the deformation of a medium in the sensor, convert it into voltage output, and then convert it into the absolute value integral of acceleration. Through sensors placed in five different positions of the body, the activity of the subject is dynamically recorded and millions of data during the activity process are recorded. The movement speed and movement mode of the body are identified according to the different acceleration changes of multiple axial planes in multiple acceleration sensors, and each second, step and action of the subject are recorded in detail, After the test, download the data from ideaa to the computer, and convert the downloaded data through the ideaa program software of minsum company. The establishment of energy consumption prediction equation can quantify the acceleration count of the original output into the active energy consumption value.

\section{RESULTS AND ANALYSIS}

There is a very significant correlation between body weight and energy consumption of Taijiquan. Energy consumption increases with the increase of body weight, mainly because energy consumption reflects the activity of all oxygen consuming tissues, that is, the greater the body weight, the more active cells involved in metabolism, and the greater the oxygen consumption; There is a significant correlation between age and energy consumption of Taijiquan. Generally speaking, exercise energy consumption shows a downward trend with the increase of age, which is mainly due to the decline of metabolic rate and basic metabolic energy consumption caused by the aging of various organs with age; Gender is also significantly correlated with their exercise energy consumption. Generally speaking, women's exercise energy consumption is lower than men's, which is mainly because women's weight is lower than men's and their metabolism level is lower, resulting in lower overall energy consumption level; There is a high significant correlation between height and energy consumption of Taijiquan, mainly because generally speaking, the greater the height, the greater the weight, but there is also a disproportion between height and weight, so there is no linear correlation between height and weight.

According to the analysis of the age of practitioners and the energy consumption of Taijiquan, in general, there is a certain negative correlation between the age of practitioners and the energy consumption of Taijiquan, $\mathrm{r}=-0.207, \mathrm{P}<0.05$; However, there was no significant correlation between male age and energy consumption of Taijiquan, $\mathrm{r}=-0.065, \mathrm{P}>0.05$; There 
Article History: Received: 28 October 2021 Revised: 05 December 2021 Accepted: 10 January 2022 Publication: 28 February 2022

was a very significant negative correlation between female age and energy consumption of Taijiquan, $\mathrm{r}=-0.277, \mathrm{P}<0.01$. This shows that the energy consumption of Taijiquan decreases gradually with the increase of age; There is no correlation between the energy consumption of male practitioners in Taijiquan and age, so the energy consumption does not necessarily decrease with the increase of age; In general, there is a significant negative correlation between age and energy consumption, but there is no significant correlation between men, which may be related to the small sample size.

It can be seen from Table 2 that by analyzing the age of practitioners and energy consumption of Taijiquan through correlation and regression, the equation between age and energy consumption of Taijiquan practitioners is as follows: $\mathrm{y}=16.23-0.042 *$ age, and there is a significant correlation between Taijiquan energy consumption and age $(\mathrm{R} 2=0.043, \mathrm{P}=0.014$ $<0.05)$

TABLE II. CORRELATION BETWEEN AGE AND ENERGY CONSUMPTION

\begin{tabular}{|c|c|c|c|c|}
\hline & $\begin{array}{c}\text { AGE } \\
\text { (YEARS) }\end{array}$ & $\begin{array}{c}\text { ENERGY CONSUMPTION } \\
(\text { KCAL) }\end{array}$ & $\begin{array}{c}\text { CORRELATION } \\
\text { COEFFICIENT }\end{array}$ & $\begin{array}{c}\text { P } \\
\text { VALUE }\end{array}$ \\
\hline Population & $53.83 \pm 12.92$ & $14.66 \pm 2.54$ & -0.207 & 0.014 \\
\hline Male $(\mathrm{n}=52)$ & $52 \pm 15.67$ & $16.39 \pm 2.22$ & -0.065 & 0.645 \\
\hline Female $(\mathrm{n}=89)$ & $54.90 \pm 10.96$ & $13.64 \pm 2.15$ & -0.277 & 0.009 \\
\hline
\end{tabular}

It can be seen from table 3 that after correlation analysis, there is a very significant correlation between the height of practitioners and the energy consumption of Taijiquan, both in general and in gender. In general, the correlation coefficient between height and Taijiquan energy consumption is $\mathrm{r}=0.66, \mathrm{P}<0.01$, and the correlation coefficient between male and female height and Taijiquan energy consumption is $\mathrm{r}=0.499, \mathrm{P}<0.00, \mathrm{r}=0.355, \mathrm{P}<0.01$, respectively. This shows that the energy consumption of Taijiquan increases gradually with the increase of height. The greater the height, the greater the energy consumption of Taijiquan.

TABLE III. CORRELATION BETWEEN HEIGHT AND ENERGY CONSUMPTION

\begin{tabular}{|c|c|c|c|c|}
\hline & $\begin{array}{c}\text { HEIGHT } \\
(\mathbf{C M})\end{array}$ & $\begin{array}{c}\text { ENERGY CONSUMPTION } \\
(\text { KCAL })\end{array}$ & $\begin{array}{c}\text { CORRELATION } \\
\text { COEFFICIENT }\end{array}$ & $\begin{array}{c}\text { PALUE } \\
\text { Population }\end{array}$ \\
\hline $163.76 \pm 7.05$ & $14.66 \pm 2.54$ & 0.625 & 0.00 \\
\hline Male $(\mathrm{n}=52)$ & $170 \pm 4.23$ & $16.39 \pm 2.22$ & 0.499 & 0.00 \\
\hline
\end{tabular}


Article History: Received: 28 October 2021 Revised: 05 December 2021 Accepted: 10 January 2022 Publication: 28 February 2022

\begin{tabular}{|l|c|c|c|c|}
\hline Female $(\mathrm{n}=89)$ & $159.54 \pm 4.45$ & $13.64 \pm 2.15$ & 0.355 & 0.001 \\
\hline
\end{tabular}

As can be seen from table 4, generally speaking, there is a significant correlation between the weight of practitioners and the energy consumption of Taijiquan, $r=0.691, \mathrm{P}<0.01$. There is also a significant correlation for different genders, in which the correlation levels between the weight of men and women and the energy consumption of Taijiquan are $\mathrm{r}=0.418, \mathrm{P}<0.01, \mathrm{r}=$ 0.6 , respectively, $\mathrm{P}<0.01$. This shows that there is a very significant positive correlation between body weight and energy consumption, and the exercise energy consumption increases with the increase of body weight

TABLE IV. CORRELATION BETWEEN WEIGHT AND ENERGY CONSUMPTION

\begin{tabular}{|c|c|c|c|c|}
\hline & $\begin{array}{l}\text { WEIGHT } \\
\text { (KG) }\end{array}$ & $\begin{array}{l}\text { ENERGY CONSUMPTION } \\
\text { (KCAL) }\end{array}$ & $\begin{array}{l}\text { CORRELATION } \\
\text { COEFFICIENT }\end{array}$ & $\begin{array}{c}\text { P } \\
\text { VALUE }\end{array}$ \\
\hline Population(n=41) & $62.36 \pm 2.18$ & $14.63 \pm 2.04$ & 0.69 & 0.000 \\
\hline Male $(\mathrm{n}=22)$ & $71.23 \pm 7.89$ & $16.3 \pm 2.69$ & 0.64 & 0.001 \\
\hline Female $(\mathrm{n}=19)$ & $58.58 \pm 7.73$ & $13.36 \pm 2.34$ & 0.574 & 0.010 \\
\hline
\end{tabular}

It can be seen from Table 5 that under the condition of the same training years, whether in terms of overall or gender, the energy consumption of practitioners with different weights is significantly correlated. Under the condition of the same training years, the greater the weight, the greater the energy consumption of completing a set of simplified 24 style Taijiquan. This shows that body weight has a great impact on energy consumption, mainly because the greater the body weight, the more active cells involved in metabolism and the greater the oxygen consumption, resulting in a large total energy consumption for completing a set of Taijiquan.

\section{TABLE V. CORRELATION ANALYSIS BETWEEN WEIGHT AND ENERGY CONSUMPTION OF PRACTITIONERS WITH DIFFERENT WEIGHTS AND THE} SAME TRAINING YEARS

\begin{tabular}{|l|c|c|c|c|}
\hline & $\begin{array}{c}\text { HEIGHT } \\
(\mathbf{C M})\end{array}$ & $\begin{array}{c}\text { ENERGY CONSUMPTION } \\
(\text { KCAL })\end{array}$ & $\begin{array}{c}\text { CORRELATION } \\
\text { COEFFICIENT }\end{array}$ & $\begin{array}{c}\text { P } \\
\text { VALUE }\end{array}$ \\
\hline Population(n=17) & $162.5 \pm 6.8$ & $14.41 \pm 1.63$ & 0.68 & 0.003 \\
\hline
\end{tabular}


Article History: Received: 28 October 2021 Revised: 05 December 2021 Accepted: 10 January 2022 Publication: 28 February 2022

\begin{tabular}{|c|c|c|c|c|}
\hline Male $(\mathrm{n}=6)$ & $169.3 \pm 6.8$ & $15.55 \pm 1.46$ & 0.667 & 0.148 \\
\hline Female $(\mathrm{n}=11)$ & $158.7 \pm 2.65$ & $13.78 \pm 1.4$ & 0.389 & 0.237 \\
\hline
\end{tabular}

\section{CONCLUSION}

The average energy consumption level of 24 Style Taijiquan changes little and always at a low level, which shows that simplified 24 Style Taijiquan is very suitable for the fitness of middle-aged and elderly people. The load intensity of amateur group is low and close to medium intensity, which shows that simplified 24 Style Taijiquan is a typical low and medium intensity aerobic exercise. The higher the technical level of the subjects, the higher the energy consumption per unit weight under the same circumstances, which to some extent shows that the higher the technical level of the practitioners, the higher the load intensity and the higher the degree of movement norms. Practitioners of different ages, different physical conditions and different exercise purposes can adjust the exercise load intensity according to different postures. Therefore, simplified 24 Style Taijiquan can meet the physical exercise of people of different ages and different exercise needs.

\section{REFERENCES}

1. R. M. Palmieri, A. Weltman, J. A. Tom, J. E. Edwards and C. D. Ingersoll (2004) "An experimental knee joint effusion does not affect plasma catecholamine concentration". Neuroscience Letters, 366(1), 76-79

2. M. Tanaka, D. Vyas, G. Moloney, A. Bedi, A. D. Pearle and V. Musahl (2012) "What does it take to have a high-grade pivot shift?". Knee Surgery Sports Traumatology Arthroscopy, 20(4), 737-742

3. G. M. Thornton, J. C. Johnson, R. V. Maser, L. L. Marchuk, N. G. Shrive and C. B. Frank (2006) "Strength of medial structures of the knee joint are decreased by isolated injury to the medial collateral ligament and subsequent joint immobilization". Journal of Orthopaedic Research, 23(5), 1191-1198

4. E. A. Wikstrom, M. D. Tillman, T. L. Chmielewski and P. A. Borsa (2006) "Measurement and Evaluation of Dynamic Joint Stability of the Knee and Ankle After Injury". Sports Medicine, 36(5), $393-410$

5. Mccosker, C., Renshaw, I., Greenwood, D., Davids, K., Gosden, E. (2019) "How Performance Analysis of Elite Long Jumping Can Inform Representative Training design Through Identification of key Constraints on Competitive Behaviours", European Journal of Sport Science, pp.1-9.

6. Markovic, G. (2007) "Does Plyometric Training Improve Vertical Jump Height? A meta-analytical Review", British Journal of Sports Medicine, 41(6), pp.349-355. 
Article History: Received: 28 October 2021 Revised: 05 December 2021 Accepted: 10 January 2022 Publication: 28 February 2022

7. Hubert, M., Starzak, M., Sadowski, J. (2015) "Does Step Length Adjustment Determine take-off Accuracy and Approach Run Velocity in Long and Triple Jumps?", Human Movement, 16(3), pp.124-129.

8. Bayraktar, I., Çilli, M. (2018) "Estimation of Jumping Distance using run-up Velocity for Male Long Jumpers", Pedagogics, Psychology, Medical-biological Problems of Physical Training and Sports, 22(3), pp.124-129.

9. Rodríguez-Rosell, D., Torres-Torrelo, J., Franco-Márquez, F., González-Suárez, J. M., GonzálezBadillo, J. J. (2017) "Effects of light-load Maximal Lifting Velocity Weight Training vs. Combined Weight Training and Plyometrics on Sprint, Vertical Jump and Strength Performance in adult Soccer Players", Journal of Science and Medicine in Sport, 20(7), pp.695-699.

10. J. H. Che, Z. R. Zhang, G. Z. Li, W. H. Tan and F. J. Qu (2009) "Application of tissue-engineered cartilage with BMP-7 gene to repair knee joint cartilage injury in rabbits". Knee Surgery Sports Traumatology Arthroscopy, 18(4), 496-503 